\title{
Estrategia familiar de reproducción en los cosecheros de frutilla procedentes de Chaco radicados en el distrito de Coronda
}

\author{
JAVIER CASTELNUOVO \\ Facultad de Humanidades y Ciencias, Universidad Nacional del Litoral, Argentina \\ javier_castelnuovo@yahoo.com.ar
}

\section{RESUMEN}

En las últimas décadas del siglo pasado comienza a manifestarse un cambio en la modalidad migratoria en los cosecheros de frutilla que desarrollan su actividad en la zona productora de frutilla de Coronda consistente en el abandono gradual de la modalidad migratoria estacional o temporaria por el asentamiento definitivo en los distritos que la conforman. Dicha situación no solamente se manifiesta en el desarrollo de nuevas zonas de asentamientos, sino que lleva el interés al análisis de las diferentes estrategias familiares de reproducción empleadas por los sujetos. Por lo tanto, es objetivo de la presente investigación indagar sobre las condiciones de vida de los cosecheros mediante estrategias de triangulación metodológica que incluyen la utilización de métodos etnográficos y la realización de entrevistas semiestructuradas a diferentes actores implicados con el fenómeno de estudio, como también el uso de fuentes censales.

PALABRAS CLAVE: modalidad migratoria; estrategias familiares de reproducción, condiciones de vida 


\section{ABSTRACT}

FAMILY REPRODUCTION STRATEGY IN STRAWBERRY HARVESTERS FROM CHACO BROADCASTED IN CORONDA DISTRICT. YOUR INCIDENCE IN THE CHANGE OF MIGRATORY MODALITY

In the last decades of the last century it began to manifest a change in the migratory modality in the strawberry harvesters that develop their activity in the production zone of Strawberry of Coronda, consisting this in the gradual abandonment of the seasonal or temporary migratory modality for the settlement definitive in the districts that make up this production area. This situation not only manifests itself in the development of new settlement zones, but also leads to the analysis of the different family reproduction strategies used by these subjects. Therefore is the objective of this research to investigate the living conditions of the harvesters through strategies of methodological triangulation that include the use of ethnographic methods and semi-structured interviews with different actors involved with the phenomenon of study, as well as also the use of census sources.

KEYWORDS: migratory modality; family strategies of reproduction, living conditions 


\section{RESUMO}

\section{ESTRATEGIA FAMILIAR DE REPRODUÇAO NOS COLHEITEROS DE MORANGO PROCEDENTES DO CHACO RADICADOS NO DISTRITO DE CORONDA. SUA INCIDENCIA NA MUDA DE MODALIDADE MIGRATORIA}

Nas últimas décadas do século passado começa a se manifestar una muda na modalidade migratória nos colheiteros de morango que desenvolvem sua atividade na Zona Produtiva de Morango de Coronda, consistente no abandono gradual da modalidade migratória estacional o temporária pelo assentamento definitivo nos distritos que conformam essa zona produtora. Essa situação não só se manifesta no desenvolvimento de novas zonas de assentamentos, mas leva o interesse ao análises das diferentes estratégias familiares de reprodução utilizadas por esses sujeitos. Portanto, o objetivo desta pesquisa é investigar as condições de vida dos colhedores por meio de estratégias de triangulação metodológica que incluem o uso de métodos etnográficos e entrevistas semi-estruturadas com diferentes atores envolvidos com o fenômeno de estudo, bem como também o uso de fontes censitárias.

PALAVRAS-CHAVE: modalidade migratória; estratégias familiares de reprodução; condições de vida 


\section{Introducción}

La zona productora de frutilla de Coronda comprende una franja de 30 $\mathrm{km}$ dirección norte-sur por $5 \mathrm{~km}$ de ancho ubicada en el centro-este de la provincia de Santa Fe, sobre la margen derecha del río Coronda conformada por los distritos de Coronda, Desvío Arijón y Arocena.

En virtud de la dinámica propia de la actividad y considerando la demanda de mano de obra, que son superiores en el período de cosecha con relación al resto de las etapas productivas, tradicionalmente arribaban a esta instancia miles de braceros procedentes de otras áreas geográficas, muchos de los cuales «alternaban» esta actividad productiva con otras actividades con similar requerimiento en lo que respecta a la demanda de mano de obra.

Dentro de estos contingentes sobresalen, por su representatividad, los procedentes de la provincia de Chaco. Su presencia en la zona productora de frutilla de Coronda, y más precisamente en el distrito de Coronda, data de la década de 1960. Estos «rotaban» la actividad de la frutilla con el algodón y el desmonte en su provincia natal, durazno y cítricos en San Pedro, el cordón frutihortícola en Mar del Plata (ambas en provincia de Buenos Aires), la uva en las provincias cuyanas, entre otros.

El carácter cíclico en estas actividades llevó a encuadrar a estos movimientos dentro de «modalidad» migratoria estacional o temporaria. Este hecho derivó en la identificación de los sujetos que llevaban adelante esta "modalidad» migratoria como «migrantes golondrina». ${ }^{1}$ En la idiosincrasia del corondino aún persiste el ideario de que la frutilla es recolectada por los «migrantes golondrina».

Este tipo de movimientos - migraciones estacionales - se caracterizaba por presentar origen y destinos variables, por el mantenimiento de la residencia en el lugar de partida, la permanencia por un período corto y variable en el destino, cuya duración fluctuaba entre tres y seis meses (Rodríguez y Venegas, 1986, en Bardomás, 2012). Las migraciones

1 Si bien en un primer momento se identificó como «golondrina» a los migrantes estacionales que llegaban por pocos meses desde Europa — principalmente de Italia y de España para desarrollar las tareas de levantar la cosecha, beneficiados por los bajos costos de transporte y los buenos salarios que percibían les permitían efectuar el viaje y obtener una suma apreciable de ganancia (Reboratti, 1979), posteriormente se amplió esta denominación a todos aquellos migrantes que, de manera cíclica desenvolvían su actividad en distintas actividades agrícolas a lo largo de todo el país. 
estacionales no implican una ruptura entre el lugar de origen y destino, aunque existe un período de ausencia del lugar de residencia habitual que puede ser muy variable (Bendini et al., 20I4). En cuanto a su carácter funcional, los autores Sabalaian y Reboratti (1980) postulan que en su mayoría estos movimientos se desenvuelven dentro del ámbito rural conformando mecanismos de complementación entre estructuras agrarias diferentes, una con exceso de mano de obra, la otra con un requerimiento circunstancial de la misma.

En los últimos 30 años se ha observado un cambio en la modalidad migratoria de los cosecheros de frutilla oriundos de la provincia de Chaco que realizan su actividad en la zona productora de frutilla de Coronda. Este cambio implicó el abandono gradual de la modalidad migratoria estacional por la modalidad definitiva, lo cual dio paso a la radicación definitiva en algunas de las áreas donde estos sujetos desempeñaban su actividad laboral. Es objeto de análisis de este artículo centrarnos sobre la situación de aquellos cosecheros radicados en el distrito de Coronda, considerando no solo al cosechero sino a a su núcleo familiar, y de esta manera poder identificar las diferentes estrategias familiares de reproducción desarrolladas dentro del nuevo contexto espacial y detectar los indicadores socioeconómicos que mayor incidencia revisten en el mejoramiento de sus condiciones de vida.

\section{Aspectos metodológicos}

El desarrollo de la presente investigación se lleva adelante empleando un marco metodológico cualitativo. No obstante, es oportuno remarcar que, ante determinadas demandas propias del proceso de investigación, se emplearon técnicas y procedimientos relacionados con la metodología cuantitativa. El abordaje cuali-cuantitativo y la estrategia de triangulación metodológica seleccionados permiten iniciar la investigación a partir de una plataforma conceptual acerca del nuevo perfil de migrante estacional, los condicionantes del movimiento, las trayectorias espaciales, los circuitos laborales y el significado social del desplazamiento (Bendini et al., 2006).

De esta manera, el proceso de exploración literaria, antecedentes, documento y datos vinculados con la problemática de estudio fue complementado con el desarrollo de entrevistas realizadas a los cosecheros nativos en la provincia de Chaco y que están radicados en el distrito de Coronda, 
cuyo testimonios serán incorporados a fin de lograr una mayor comprensión de la problemática trabajada en el artículo. Es así como la selección de unidades acotadas - cosecheros de frutilla radicados en Coronda provenientes de la provincia de Chaco_- ofrece la posibilidad de cambiar referencias estadísticas con diversas estrategias, que incluyen la utilización de métodos etnográficos y la realización de entrevistas semiestructuradas a diferentes actores implicados con el fenómeno de estudio.

Si bien las entrevistas fueron efectuadas a diferentes actores partícipes de la producción de frutilla, entre los que se destacan productores, funcionarios municipales, autoridades de establecimientos educativos, entre otros, el mayor peso fue otorgado al relato que los propios cosecheros brindaron sobre su experiencia de vida. Fueron efectuadas en las viviendas de los cosecheros, localizadas mayormente en terrenos correspondientes al ferrocarril Belgrano, en cercanías a las quintas donde se desempeñan laboralmente; se desarrollaron en hora de la siesta, cuando ellos ya culminaron su actividad. Se tomó como muestra el número aproximado de 30 cosecheros (I5 radicados en el sector norte del casco urbano histórico de Coronda y los otros Is radicados en el sector sur). Esta elección se justifica por el hecho de evitar distorsiones en los resultados que el factor distancia por cercanía que la presencia de familiares o coterráneos podría llegar a suponer.

Como complemento de instrumentos referidos al componente cualitativo empleado, desde la perspectiva cuantitativa se utilizan como principal referencia datos proporcionados por el Censo de Población Hogares y Vivienda realizado por el Instituto Nacional de Estadística y Censos (INDEC) correspondiente al año 20012 sobre la población oriunda de Chaco radicada en el distrito de Coronda, 3 lo que permite sumar una perspectiva macro al universo más acotado que ofrecen las entrevistas.

2 La utilización de este Censo obedece al hecho de que los datos publicados correspondientes al último Censo - 2010 — no está disponible la información correspondiente a la población según provincia de nacimiento. También es inoportuno el análisis de unidades menores, como ser radios censales utilizando dicha fuente, por el hecho que la misma no discrimina la población según lugar de nacimiento.

3 Las unidades de censales de análisis que se tomaron en la provincia de Chaco son los departamentos en los que se encuentran los distritos en lo que manifestaron haber nacidos los cosecheros radicados en el distrito de Coronda. De esta manera se trabajó con 10 departamentos localizados en el centro y sudoeste de esta provincia, estos son: 2 de Abril, 9 de Julio, 25 de Mayo, Fray Justo Santa María de Oro, Gral. Güemes, Independencia, Myor. L. Fontana, O'Higgins, Quitilipi, San Lorenzo. 


\section{Los cosecheros de frutillas provenientes de la provincia de Chaco en el distrito de Coronda. Su estadía}

Si bien, como se menciona en párrafos precedentes, en las últimas décadas el cambio en la modalidad migratoria lleva a la radicación definitiva de cientos de cosecheros de frutilla procedentes de la provincia de Chaco en el distrito de Coronda, su situación en cuanto a condiciones laborales y de vida no han variado mayormente. Estas condiciones son de extrema vulnerabilidad y la precariedad laboral propia de la actividad acentúa las carencias que sobrelleva su vida.

Sabemos que los trabajadores estacionales dedicados a las actividades primarias suelen ubicarse dentro de los estratos más relegados de la economía, «históricamente han sido en la Argentina uno de los sectores menos protegidos y de mayor riesgo laboral por el índice de trabajo en negro, sin formalización de su vínculo contractual» (Bendini et al., 20I2:72). En ocasiones, la propia estacionalidad en sus labores se constituyó en la base de su vulnerabilidad, sumada a la peregrinación a lo largo del país siguiendo el ritmo de cosecha de diferentes cultivos. Como lo afirman las autoras Bendini, Radonich, Steimbreger: «los migrantes estacionales han sido y son los más vulnerables debido a su invisibilidad social y a su mayor desprotección legal (73).

\section{Composición demográfica de la población procedente de Chaco en el distrito de Coronda}

Según los datos del Censo correspondiente al año 200I, el 83,2 \% de la población del distrito de Coronda nació en la provincia de Santa Fe y, dentro de esta, el 90,I \% en el distrito de Coronda; el resto, en otros distritos o parajes de la misma provincia. La población nacida en la provincia de Chaco residente en este distrito ascendía a I246 personas, lo cual representaba el 7,4\% de la población total del distrito, convirtiéndose en la mayor participación de población no nacida en la provincia de Santa Fe, secundada por Buenos Aires y Entre Ríos, con una participación considerablemente menor, I, $8 \%$ y I, $6 \%$, respectivamente.

La población nacida en las provincias de Santa Fe y Chaco representan el 90,6\% de la población total del distrito. En cuanto a la composición por género, según la misma fuente, dentro de la población nacida en la provincia de Chaco hay una marcada supremacía de población mascu- 
lina, siendo el índice de masculinidad 171,5, valor claramente superior en relación con el índice de la población nacida en la provincia de Santa $\mathrm{Fe}(\mathrm{IO} 8,4)$. El índice total del distrito era de II2,7.

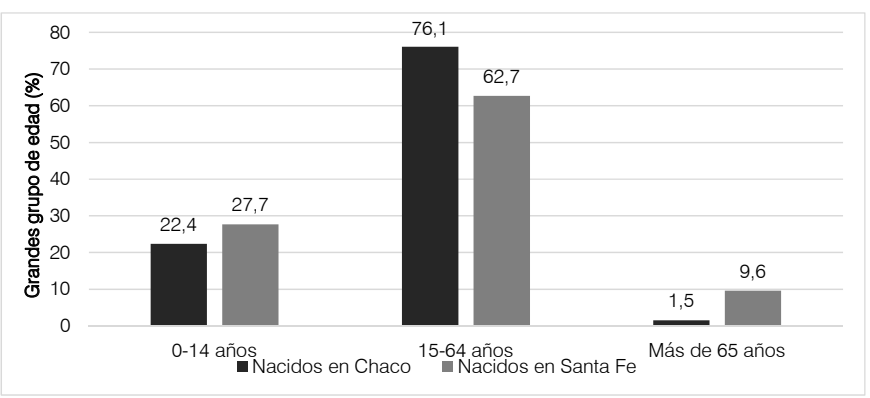

Figura 1. Porcentaje de la población de Coronda en grandes grupo de edad, según esta sea nacida en Chaco o en la provincia de Santa Fe. Año 2001.
Fuente. elaboración propia sobre la base de datos correspondiente al Censo de Población, Hogares y Viviendas, 2001 (INDEC).

La población nacida en la provincia de Chaco, según grupos etarios, presenta una supremacía de población adulta, mientras que la población envejecida es prácticamente insignificante (Figura I). Dentro de la población activa se produce una fuerte concentración de la población en el grupo etario comprendido entre los 15 y 29 años, el cual representa el $58,6 \%$ de la población activa y el 44,5\% de la población nacida en Chaco. Deducimos, entonces, que estas edades son las que mayor presencia tienen en la actividad de la cosecha.

\section{Principales estrategias de reproducción familiar de los cosecheros de frutilla. Su incidencia en la radicación en el distrito de Coronda}

El cambio en la modalidad migratoria y la radicación definitiva en el distrito de Coronda de los cosecheros de frutilla oriundos de Chaco se debe, por un lado, a las posibilidades en el desempeńo laboral, principalmente por la extensión del período de cosecha de la frutilla, que de 3 meses pasó a 6 o 7, como también a las mayores oportunidades para realizar actividades alternativas (generalmente encuadradas dentro de las denominadas «changas»). 
Esta situación supone el desarrollo de nuevas estrategias familiares de reproducción orientadas a la mejora de sus condiciones de vida considerando su lugar de procedencia. Las estrategias familiares de reproducción «hacen referencia a las acciones más o menos deliberas para lograr mantener o mejorar sus condiciones de vida y/o su estatus social a lo largo del tiempo" (Bendini et al., 20I2). Estas estrategias se desarrollan dentro de un contexto témporo-espacial en el cual cada familia toma decisiones para el logro de sus objetivos. Estos objetivos involucran decisiones respecto de determinados ciclos de vida familiar, de organización de la vida doméstica, la cooperación familiar y extrafamiliar. En el caso particular de los cosecheros de frutilla, el peso de estas estrategias está dado desde lo individual a las posibilidades de inserción dentro del mercado laboral local, considerando el plano familiar el desarrollo de estrategias que se vinculan a la posibilidad de acceder a un terreno donde construir su vivienda, contar con servicios básicos a los que esta población en parte estaba relegada, como, por ejemplo, acceso al agua, electricidad, atención sanitaria, acceso a la educación, entre otros. En adelante, se atenderá su situación en cuanto al acceso a estos servicios en comparación a la de su provincia natal.

\section{Hábitat de los cosecheros de frutilla radicados en Coronda}

La precariedad en las condiciones de vida mantiene una relación directa con la vulnerabilidad de los seres humanos. Toda persona que no cumple con condiciones mínimas de vida se ve violada en sus derechos. Las condiciones de vida están emparentadas con los lugares donde los trabajadores desarrollan su cotidianeidad e incluye desde sus lugares de trabajo, espacios de socialización, ámbitos donde sus hijos llevan adelante actividades recreativas, tan básicas como el de contar con un campito para jugar a la pelota con sus amigos o tener desmalezados los caminos para que puedan ir a la escuela sin correr riesgos, hasta la accesibilidad a servicios de infraestructura básicos.

En el momento en que los migrantes temporarios deciden cambiar su modalidad migratoria para radicarse en Coronda se da a un cambio radical en la organización del espacio de esta localidad. Surgen asentamientos, principalmente en terreno correspondiente al Ferrocarril Gral. 
Belgrano, ${ }^{4}$ tanto hacia el norte (Figura 2) como hacia el sur (Figura 3) del casco urbano histórico (Figura 4), alterando la fisonomía y produciendo el surgimiento de una franja perirurbana en la cual se da un incremento tanto en el intercambio físico de personas, mercaderías, como en las representaciones sociales de estos sujetos.

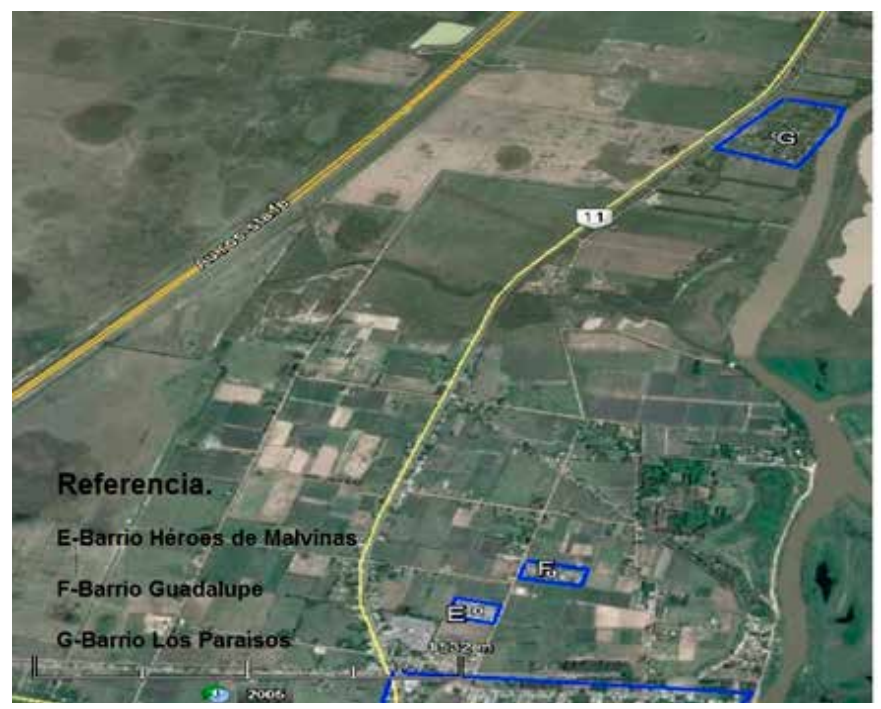

Fuente. Google earth.

Figura 2. Distrito de Coronda sector norte.

4 La construcción de viviendas sobre terrenos correspondiente al Ferrocarril Gral. Belgrano no es casual, sino que es parte de una estrategia empleada por parte de los cosecheros ante posible intento de desalojo por parte del gobierno local que, al no tener jurisprudencia sobre estos terrenos, se vio imposibilitado de llevar adelante cualquier acción. 


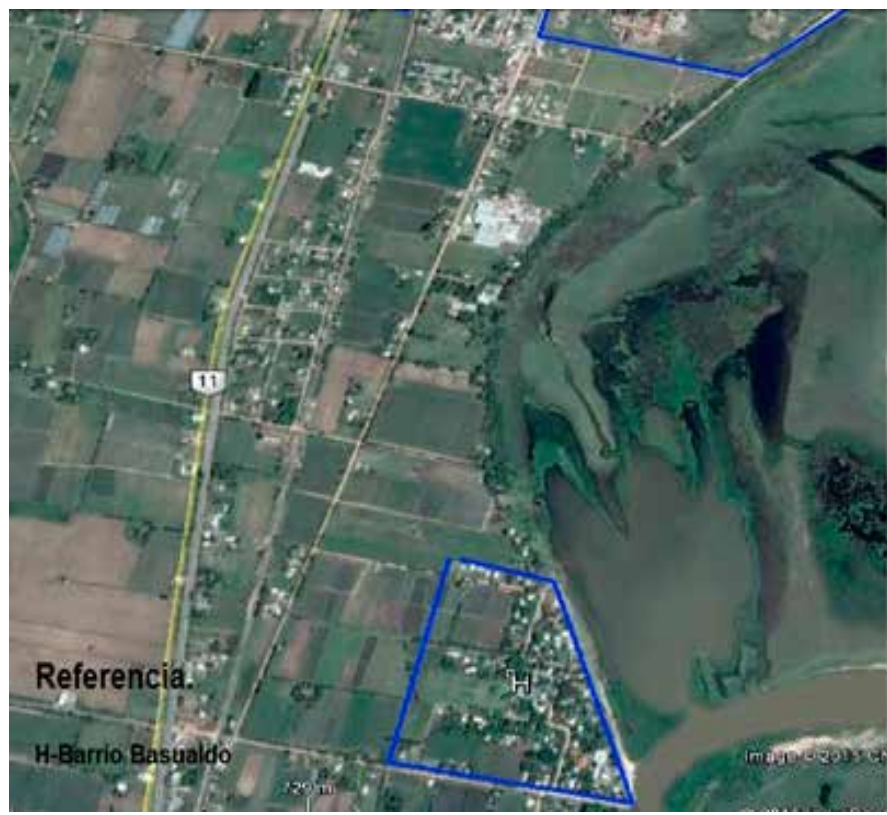

Figura 3. Distrito de Coronda sector sur.

Fuente. Google earth.

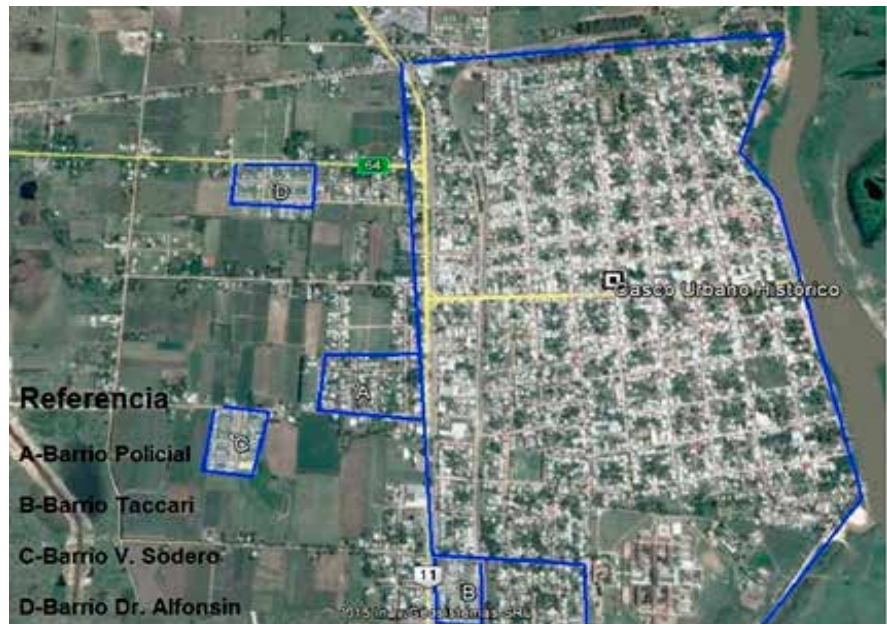

Figura 4. Distrito de Coronda. Sector central (casco urbano histórico). 
Es necesario mencionar que entendemos por hábitat a la interrelación que se genera entre medio social y físico, con intersección entre sociedad y espacio (Gutman 1989, en Benencia, 1999). El hábitat de los pobladores del área está constituido por tres círculos concéntricos que tienen su eje en un patio central (zona de paso) alrededor del cual se levanta una serie de construcciones (la vivienda humana) que conforman el primer círculo. Inmediatamente respecto de este, un segundo anillo donde se ubican las construcciones dedicadas a los animales domésticos (gallineros, chiqueros, corral), la huerta, allí se incluye la letrina y, a continuación, en una tercera franja, las tierras dedicadas a la producción - quintas de frutilla - (adaptación realizada sobre la base de la tipología desarrollada por Benencia, 1999).

La localización de los cosecheros usurpando los terrenos correspondiente al ferrocarril responde a dos cuestiones estratégicas, por un lado, se aseguran su permanencia ya que el Municipio no tiene potestad para desalojarlos y, por otra parte, estos buscan construir la vivienda en cercanía de las explotaciones en las que son empleados. De esta manera, se va conformando un mundo social que encierra relaciones en las que estos sujetos van recreando su vida. La configuración es similar a lo acontecido en el Alto Valle del Río Negro, donde estos tipos de asentamientos son conocidos como "calles ciegas", por $10^{5}$ que, considerando la característica y la disposición a la largo de las vías del ferrocarril, para el caso del distrito de Coronda le cabría la denominación de «calle ramal».

\section{Acceso al terreno y estado de las viviendas}

$\mathrm{El}$ acceso al terreno no constituye un problema para estos sujetos. Al asentarse sobre terrenos correspondientes al ferrocarril, sabían que su desalojo no era una cuestión sencilla de realizar; de esta manera, a medida que iban llegando, se adueñaban del terruño, lo desmalezaban y empezaban a construir su vivienda con material de extrema precariedad —nylon, cartón, mulching.

5 En el Alto Valle del Río Negro se utiliza la denominación de «calles ciegas» para explicar la forma lineal que adoptaron muchos caseríos, cuyos habitantes fueron construyendo «tiras de viviendas» en los bordes de canales o desagües, a la vera de caminos de escasa circulación o en la ribera de los ríos (Radonich et al., 2012:248). 
El conocimiento previo que la mayoría de ellos tenían sobre el lugar - por haber desempeńado por ańos la actividad en la zona-, sumado a los contactos, producto de los vínculos establecidos en el lugar, fue de gran ayuda al momento de radicarse. Los primeros cosecheros, una vez instalados en el nuevo espacio, sirvieron de apoyo a los nuevos, brindándoles asistencia básica durante los primeros días de estadía —ayuda en el desmalezado del terreno, colaboración a la hora de construir la vivienda, contactos con patrones para conseguir trabajo - hasta que estos estuvieran en condiciones de asentarse.

Uno de los indicadores con mayor importancia de analizar al momento de evaluar las condiciones de vida en una población es el de la vivienda. Independientemente de las diversas pautas culturales y la escala de valores de cada sociedad, existe un núcleo irreductible de indicadores cuya satisfacción inciden de manera directa en la calidad de vida de los habitantes. Dentro de estos indicadores se encuentran aquellos relacionados con la calidad de la vivienda, referidos específicamente a los materiales con la que están construidas y los servicios de infraestructura, dentro de los que se incluyen la disponibilidad de agua potable, las características sanitarias, etcétera.

La vivienda expresa la voluntad de arraigo del hombre en el paisaje y revela la capacidad de sus ocupantes para adaptarse a las condiciones de su ambiente natural, respondiendo a las exigencias de su género de vida, al tipo de tenencia de la tierra, a los recursos económicos de que dispone, las circunstancias históricas, etc. (Pértile, 2013). Esta consideración es ampliada por Alejandra Fantín (2008), quien recurre a la siguiente cita para sintetizar la relación entre las características de las viviendas y las condiciones de vida:

Las condiciones de la vivienda, al igual que de pobreza, estratifican socioeconómicamente a una población, dado que representan una "traducción" del ingreso a las condiciones materiales de la existencia. Por otro lado, la vivienda, posee un significado propio. Sus características tienen determinantes geográficos, climatológicos y culturales importantes. Dependen también de características comunitarias, como la disponibilidad de servicios básicos: agua, drenaje, hacinamiento, material de los pisos, etc. (Infante y Schlaepfer, 1994, en Fantin, 2008)

Dentro de la tipología correspondiente a la variedad de vivienda rural, la de los cosecheros constituye el eslabón más precario, y aun así dentro de estas se visualizan diferencias. 
La construcción de la vivienda se realiza con los elementos que encuentran a "mano", que van desde el sobrante de mulching de polietileno, que utilizan para cubrir los surcos, pasando por cajas de cartón que piden en almacenes cercanos, hasta madera, chapa o adobe. El tema es contar con una construcción que le permita estar al resguardo ante determinadas inclemencias, como el frío-calor, lluvia, viento, y le ofrezca, aunque sea, la mínima sensación de intimidad. A unos metros de la vivienda principal — que por lo general no posee más de dos cuartos, excepcionalmente tres - se encuentra la letrina, que en la mayoría de los casos consiste en un cuadrado de un metro por un metro con una rama en cada extremo que sirve de soporte para que pueda ser «rodeada" por nylon o cartón, y muy rara vez cuenta con techo. A medida que pasa el tiempo, las construcciones se van consolidando y se puede ver el empleo de materiales más resistentes, aunque no por esto dejan de ser precarias. De esta manera, se pueden diferenciar entre las viviendas correspondientes a los cosecheros con menor tiempo de estadía en el distrito y las viviendas más consolidadas correspondientes a los de mayor antigüedad. En ambos casos predomina la precariedad en su construcción, siendo más severa la situación en el primero.

$\mathrm{Si}$ consideramos los datos correspondientes al Censo del año $200 \mathrm{I}$ vinculados con la calidad de los materiales con la que están construidas las viviendas, podemos observar que en el área rural (zona donde se encuentran preferentemente asentados estos sujetos) el 4I,5\% de las mismas se encuadra dentro del tipo de vivienda CALMAT IV que, según tipología confeccionada por el INDEC, corresponde a viviendas que presentan materiales no resistentes ni sólidos o de desecho al menos en uno de los parámetros; y el 25,5\% se encuadra dentro del tipo de vivienda CALMAT III, que corresponde a viviendas que poseen materiales resistentes y sólidos en todos los parámetros pero le faltan elementos de aislamiento o terminación en todos sus componentes o bien tienen techos de chapa de metal o fibrocemento u otros sin cielorraso; o paredes de chapa de metal o fibrocemento. La existencia de las viviendas encuadradas dentro de las categorías de menor calidad —CALMAT III, CALMAT IV— adquiere mayor significancia dentro del área rural con relación al área urbana (Figura 5).

Otro indicador revelador de la precariedad de las viviendas lo constituye el tipo de vivienda. ${ }^{6} \mathrm{Al}$ contemplar la situación de las personas nacidas

6 Las variables aplicadas al presente objeto de estudio para el tipo de vivienda particular empleada por el INDEC son las siguientes: 
en la provincia de Chaco, encontramos que el 49,6 \% residía en «rancho/ casilla", mientras que el 35,9 \% lo hacía en Casa Tipo B, un común denominador para estas tres categorías — «rancho, casilla», Casa Tipo B- es que presentan uno o más elementos deficitarios en su construcción; en tanto solo el iI, $8 \%$ residía en viviendas sin elementos deficitarios, encontrándose todas estas dentro de la categoría Casa Tipo $\mathrm{A}^{7}$ (Figura 6).

Fuente. elaboración propia sobre la base de datos Censo de Población, Hogares y Viviendas. Año 2001 (INDEC).

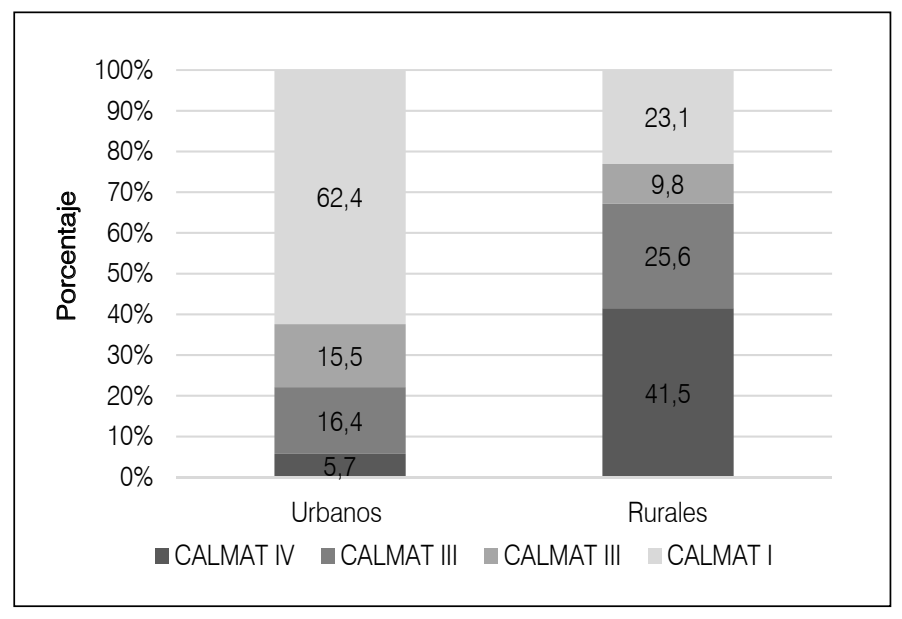

Figura 5. Distrito de Coronda. Hogares urbanos y rurales por calidad de materiales de la vivienda (CALMAT). Año 2001.

Casa Tipo A: vivienda con salida directa al exterior /sus habitantes no pasan por pasillos o corredores de uso común) construida originariamente para que habiten personas. Generalmente tiene paredes de ladrillo, piedra, bloque u hormigón. No tienen condiciones deficitarias.

Casa Tipo B: casa que presenta al menos una de las siguientes condiciones deficitarias: tiene piso de tierra o ladrillo suelto u otro material (no tiene piso de cerámica, baldosa, mosaico, mármol, madera, alfombra, cemento o ladrillo fijo); o no tiene provisión de agua por cañería dentro de la vivienda, o no dispone de inodoro con descarga de agua.

Rancho: vivienda con salida directa al exterior (sus habitantes no pasan por pasillos o corredores de uso común) construida originalmente para que habiten personas. Generalmente tiene paredes de adobe, piso de tierra y techo de chapa o paja. Se considera propia de áreas rurales.

Casilla: vivienda con salida directa al exterior, construida originalmente para que habiten personas (sus habitantes no pasan por pasillos o corredores de uso común). Habitualmente está construida con materiales de baja calidad o de desecho y se considera propia de áreas urbanas.

7 En Argentina, desde el Censo Nacional de Población y Vivienda de 1980, se han incorporado, al tipo de vivienda «casa», los conceptos de casa de tipo «A» y casa de tipo «B» a efectos de discriminar, según características estructurales y accesibilidad a servicios, condiciones de mayor o menor habitabilidad de las mismas (Fantín, 2008). 


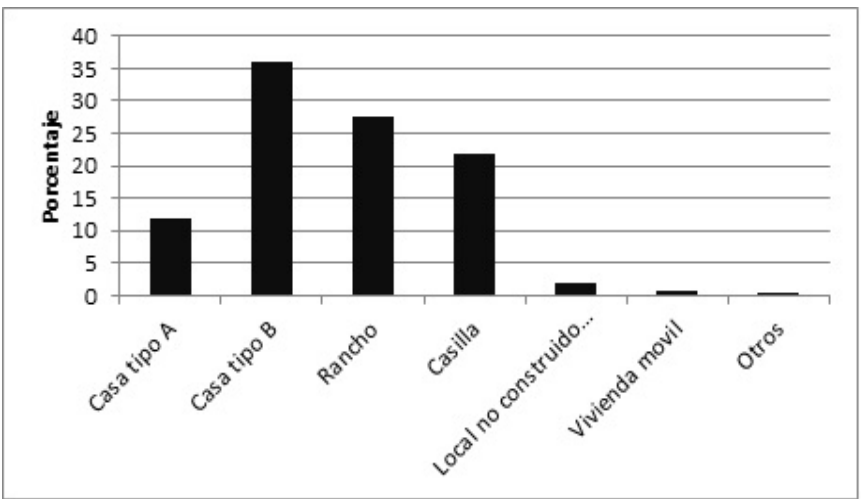

Figura 6. Distrito de Coronda. Población nacida en la provincia de Chaco según tipo de vivienda. Año 2001.
Fuente: elaboración propia sobre la base de datos Censo de Población, Hogares y Viviendas. Año 2001 (INDEC).

\section{Hacinamiento}

Otro de los indicadores que se relaciona con la precariedad de las viviendas es el hacinamiento. El INDEC considera que se está en situación de hacinamiento cuando residen tres o más personas por cuarto. En el caso de la población de estudio, se puede identificar la conjunción de dos circunstancias, por un lado, la precariedad en la construcción de las viviendas y, por otro, el tamaño. Si a esta situación se la combina con el elevado número de hijos que suelen tener los cosecheros, se produce un agravamiento. Según datos correspondientes al Censo de Población, Hogares y Viviendas del año 200I, el 48,3 \% de la población nacida en la provincia de Chaco radicada en el distrito de Coronda se encontraba en situación de hacinamiento, en tanto que la media para el distrito era de $14,8 \%$. Al relacionar el hacinamiento con el tipo de vivienda, la realidad indica que el $65,5 \%$ de la población que residía en vivienda tipo «rancho» se encontraba hacinada, y el 53,7 \% de la población residente lo hacía en vivienda tipo «casilla».

\section{Acceso a los servicios y calidad de vida}

Los servicios sociales son uno de los elementos fundamentales al momento de evaluar las condiciones de vida en determinada población. El acceso a los mismos es un punto decisivo en el cambio de modalidad migratoria y el consiguiente establecimiento definitivo de los cosecheros en el distrito 
de Coronda. Los resultados que se reflejan en el Censo, complementados con relatos en las entrevistas realizadas a los cosecheros, marcan una clara ventaja en cuanto al acceso de estos en el distrito de Coronda respecto de los distritos localizados en el área de expulsión.

Agua, divino tesoro

La disponibilidad de agua potable, dados los atributos que presenta, en especial desde el punto de vista de la higiene y la prevención de enfermedades, debería ser contemplada como una cuestión de Estado, un derecho básico de cada habitante en su lugar de residencia.

El acceso al agua salubre y a medios higiénicos de evacuación de excretas es una necesidad universal para el desarrollo humano y la eliminación de la pobreza y un componente fundamental de la atención primaria de la salud. Está demostrado que la prestación de servicios de saneamiento adecuados, el abastecimiento de agua salubre y la educación en higiene, constituyen una intervención sanitaria eficaz que reduce la mortalidad provocada por las enfermedades diarreicas en un promedio del $65 \%$ y la morbilidad asociada en un $26 \%$. (OPS, 2000, en Fantín, 2008)

La importancia en el diagnóstico de la población con carencia en la procedencia y suministro de agua en Argentina presenta un dilema ya que, si bien, por un lado, es medible por el INDEC en los Censos de Población, Hogares y Vivienda, no es considerada por dicho organismo como una necesidad básica. Sobre este aspecto cabe resaltar que nuestro país y Perú son los únicos en el contexto latinoamericano que no contemplan el acceso a agua potable como necesidad básica.

La calidad del agua y el acceso continuado a la misma garantizan un mínimo de condiciones sanitarias y son una necesidad básica independientemente de la ubicación geográfica de la vivienda. La carencia de agua dentro de la misma implica una falta del elemento vital que afecta la higiene y la salud de las personas y sus familias (Domenach; Celton, 1998). En relación con la obtención de agua por parte de los sujetos, encontramos una de las principales diferencias entre el área de expulsión y el área de recepción. En este sentido, la provincia de Chaco y, en especial, los departamentos situados en el centro y sudoeste de esta, que son los de procedencia de los cosecheros, presentan severos problemas a 
la hora de acceder al agua, sea esta potable o no. «Las áreas más críticas en cuanto al porcentaje de viviendas si acceso de viviendas a agua de red se localizan en el oeste de la provincia de Chaco» (Fantín, 2008). En ocasiones, deben recorrer varios kilómetros hasta llegar a «algún pozo" en el cual puedan llenar unas cubetas de agua para llevar a su vivienda, agua que es destinada principalmente para el consumo, y a esta situación hay que agregar la pésima calidad de la misma.

Los propios cosecheros cuentan la travesía que debían realizar para obtener agua en su lugar de origen. El siguiente fragmento corresponde a la entrevista realizada a Marcos, quien establece diferencias entre ambos espacios:

Tengo acceso al agua por medio de perforación a bomba, en todo momento tengo agua. En Chaco teníamos agua de pozo que, en tiempo de sequía, había que cuidarla como oro. (Marcos, cosechero, entrevista del autor, enero de 2013)

En tanto que Mario cuenta su experiencia con relación a la obtención del agua en Charata, lugar de procedencia:

En Chaco obteníamos el agua de pozo, son enormes pozos que usted tiene que largar el balde y sacar con soga. Los pozos a veces estaban cerca otras, no tanto, en la época de calor se secaban y había que esperar que se vuelvan a cargar para poder sacar agua. En cambio, acá tenemos bomba a motor y nunca tuvimos problema con el agua. (Mario, cosechero, entrevista del autor, diciembre de 2012)

La escasez de agua no solamente era una problemática para las personas, sino que también era sufrida por los animales, y respecto de esta cuestión se relata:

En Chaco teníamos pozo nomás, no existe la bomba. Eran pozo de dos metros de por diez o doce metros de profundidad. Si tenés muchos animales, metés el motor villa y de ahí le saca a las vacas, a los animales. Hace unos años atrás había problema de sequía, había mucha sequía, muchos animales muertos, no aguantaban los pozos, no aguantaban, hasta lo último le llevaban agua potable a los animales. (Ramón, cosechero, entrevista del autor, enero de 2013) 
Con referencia al tema, en el distrito de Coronda, según datos correspondientes al Censo de Población, Hogares y Viviendas del año 200I, solamente el 2I,3\% de los cosecheros provenientes del Chaco tenía acceso a agua procedente de la red pública (potable), estos corresponden a los que arribaron y se asentaron en la primera etapa migratoria en la década de 1970-1980. La mayoría de los cosecheros que arribaron a mediados de la década de 1990 y se localizaron en el sector periurbano no tiene acceso a agua proveniente de la red pública por dos motivos: por un lado, porque no llega la extensión de la red y, por otro, en la mayoría de los casos, al estar radicados sobre terrenos del ferrocarril, por más que la extensión de red de agua potable cubra ese sector, al no poder corroborar ser propietarios del terreno no pueden acceder al servicio. Esta situación lleva a que la obtención del agua, en la mayoría de esta población, sea por medio de la perforación (Figura 7). Aquellos que no cuentan con perforación, ya sea por no disponer con los medios para realizarla o por su poco tiempo de residencia, acuden a algún vecino que lo abastece de agua.

Fuente. elaboración propia sobre la base de datos del Censo de Población, Hogares y Viviendas. Año 2001 (INDEC).

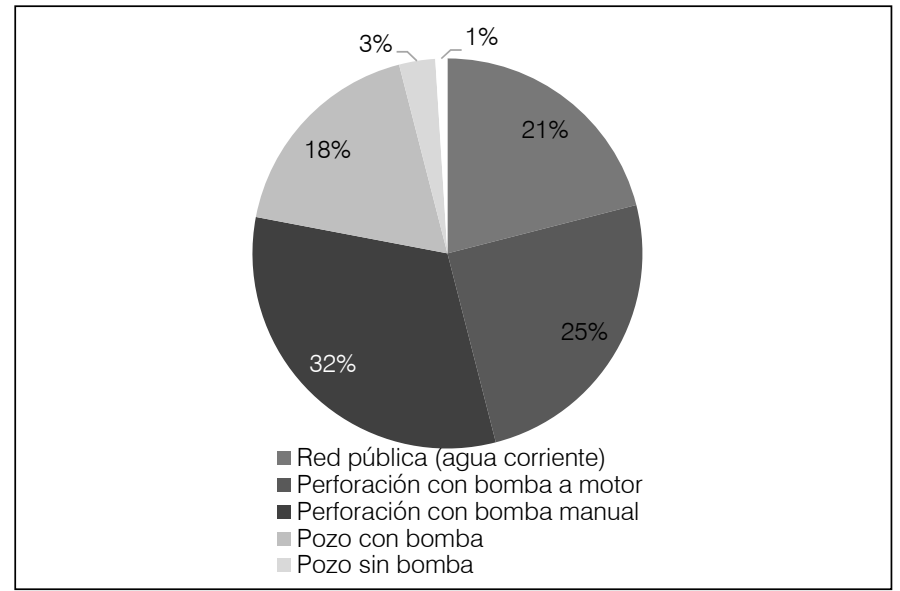

Figura 7. Distrito de Coronda. Procedencia del agua en la vivienda en población nacida en la provincia de Chaco. Año 2001.

El acceso al agua, reconocido como un servicio indispensable, constituye uno de los indicadores que más valoriza la población procedente de la provincia de Chaco a la hora de radicarse en la localidad de Coronda. Esta estimación es magnificada al considerar los problemas que tenía 
las familias para acceder al agua en su provincia de procedencia, que se pueden corroborar a través de los relatos seleccionados.

\section{Servicio sanitario como situación de vulnerabilidad extrema}

Las características relacionadas con el servicio sanitario implican el análisis de la población según el sistema de eliminación de excretas. Sobre estos aspectos, los datos ofrecidos por los censos dan cuenta de la existencia de baño/letrina en el hogar y el tipo de evacuación de las excretas, si se realiza a red pública (cloacas), pozo ciego, hoyo o pozo, en la superficie de la tierra, del río, o arroyo, etcétera.

Los valores expresados en la Figura 8 corresponden a la población nacida en la provincia de Chaco según cuenten con inodoro con descarga o no, de los cuales se advierte que el $82 \%$ se encuentra en la categoría de mayor vulnerabilidad -inodoro sin descarga o sin inodoro- De esta manera, y con relación al déficit sanitario, esta condición de precariedad constituye una transferencia propia del modo de vida y las pautas culturales de estos sujetos. Es característica distintiva del paisaje donde están asentados la localización del baño a unos pocos metros de las viviendas, en la intemperie, limitándose su construcción a un cuadrado de un metro por un metro en el cual cuatro ramas envueltas en mulching negro sirven de soporte y, dentro de este, se cava el hoyo que oficia de letrina.

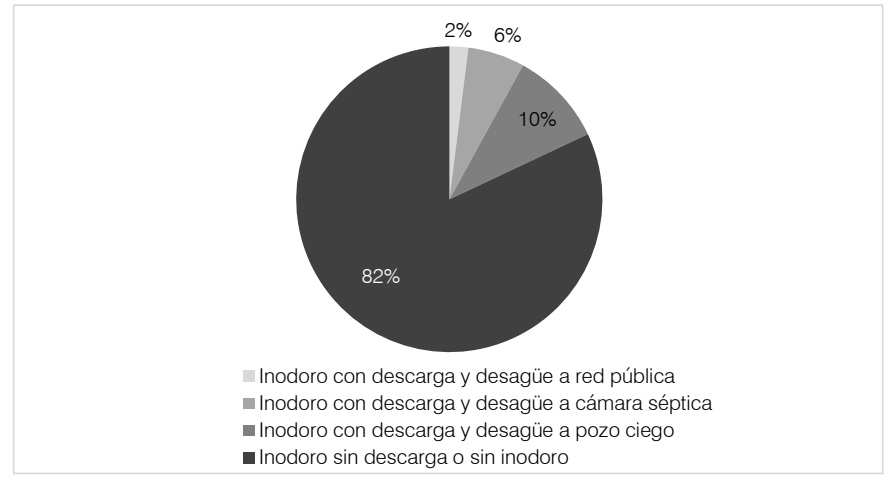

Figura 8. Distrito de Coronda. Población nacida en la provincia de Chaco según cuente con inodoro con descarga o no. Año 2001.
Fuente. elaboración propia sobre la base de datos del Censo de Población Hogares y Viviendas. Año 2001 (INDEC). 


\section{Asistencia médica}

Se advierte la situación de precariedad en la que el cosechero desarrolla su vida junto a su núcleo familiar, vinculada a las propias condiciones laborales traducidas en ingresos monetarios insuficientes para asegurar un abastecimiento adecuado y para cubrir las necesidades básicas del conjunto familiar, situación de informalidad al no estar inscripto dentro del mercado laboral y, por consiguiente, estar ajeno a los beneficios propios de la formalidad, ya que no registra aportes jubilatorios, vacaciones pagas, y tampoco posee cobertura de aseguradoras de trabajo ni médica.

En cuanto a este último punto, el poder contar con una obra social, atento a la conformación de su núcleo familiar, la presencia de centros sanitarios de atención primaria en el distrito de Coronda ha tenido su peso a la hora de optar por uno u otro lugar de residencia.

De esta manera, según relatos de los cosecheros, en su conjunto, el panorama que presenta el distrito de Coronda es superador comparándolo con el de su área de procedencia. El distrito de Coronda cuenta con tres centros de atención primaria, el SAMCo (localizado en el extremo sureste del casco urbano histórico), el dispensario San Pantaleón (ubicado en el sector noroeste del casco urbano histórico) y el dispensario Vecinal Urquiza (localizado en el barrio Basualdo). En los dos últimos centros se atienden necesidades básicas, e incluso no es constante la atención; en cambio, en el primero la atención es durante las 24 horas del todos los días de la semana, incluso casos de mayor complejidad (quebraduras, atención odontológica, pediátrica, psicológica, fonoaudiología, kinesiología, etcétera).

Todos estos centros son de gestión pública, condición de vital importancia como consecuencia de la alta informalidad en el sector de los cosecheros junto a su grupo familiar, ya que un porcentaje importante carece de obra social y/o plan de asistencia médica (Figura 9).

Sobre la situación de esta población hay que considerar dos puntos de importancia: el primero es el número elevado de niños/as dentro del conjunto de la población, siendo este grupo uno de los más vulnerables en el aspecto sanitario; el segundo es la facilidad de acceso a estos centros. Debido a que la mayoría reside en los terrenos del Ferrocarril y, estos corren paralelos a la Ruta Nacional $\mathrm{N}^{\circ}$ II, la distancia que tienen que andar hacia las paradas de colectivos de media distancia que los trasladen hacia los centros sanitarios es mínima. Esta situación cobra mayor impor- 
tancia en los cosecheros radicados en el sector norte del distrito debido a que los radicados en el sector sur cuentan con el dispensario antes mencionado. El cosechero Luis hace referencia en su relato a la influencia del factor distancia entre su lugar de origen y el distrito de Coronda:

Donde estábamos nosotros en Chaco había siete leguas al pueblo, ponele vos que llueva, te enfermás vos o yo, el patrón te va a llevar si puede, pero si llueve y llueve y te lleva y va a la cuneta un carro, eso era el problema. Acá no tenemos ese problema, cualquier cosita le digo al cumpa — señala a su amigo- y me da una manito, llama a la ambulancia y en diez minutos viene. Para mí es una buena acomodada porque te queda todo cerquita. Claro, vos decís me voy a Coronda a pie son cinco kilómetros por acá (señala un camino de tierra interno que corre paralelo a la ruta), por acá (señala la ruta) más lejos te queda, por acá son siete kilómetros, pero por acá a pie tranquilo en la bicicleta es un ratito. (Luis, cosechero, entrevista del autor, enero de 2013)

Además de disponer de estos centros primarios de salud, los especialistas médicos (odontólogos, oftalmólogos, fonoaudiólogos) dependientes del SAMCo de Coronda recorren los establecimientos educativos localizados en zona rural de manera periódica para realizar controles, en especial a la población de niños. Así, todos los viernes visitan la Escuela $\mathrm{N}^{\circ}$ I2I4 Granaderos de San Lorenzo, localizada en el extremo norte del distrito de Coronda, a la cual concurren chicos de todo el barrio, independientemente de que si asisten o no a la escuela. Sandra, quien procede de San Bernardo y hace I6 años que está radicada en el distrito de Coronda, en cercanías del establecimiento antes mencionado expresa: «al hospital la llevo a ella, sino acá al dispensario - actualmente no funciona-, o los viernes vienen a la escuela los doctores; el dentista también viene a la escuela». 
Fuente: elaboración propia sobre la base de datos Censo de Población, Hogares y Viviendas. Año 2001 (INDEC).

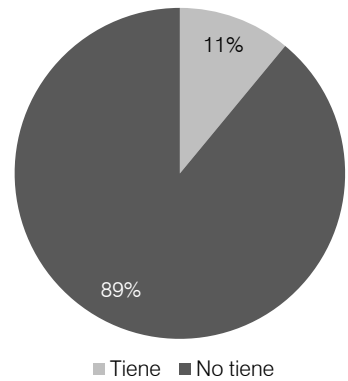

Figura 9. Distrito de Coronda. Población nacida en la provincia de Chaco según cuente con obra social. Año 2001.

En la Escuela $\mathrm{N}^{\circ} 790$ Pablo Pizzurno, localizada en el sector sur del distrito, la directora del establecimiento educativo primario manifiesta:

Estamos trabajando con la gente del SAMCo y de la Municipalidad, los asistentes sociales, y en este momento tengo nueve familias que visita la asistente social y de padres que no se interesan y no quieren enviar a los chicos a especialistas como fonoaudiólogo porque tienen problemas en expresarse, o psicólogos porque detectamos otro tipo de problema, ellos, se niegan a brindarles ese tipo de atención a sus hijos. No tenemos chicos desnutridos, si cuando vienen del hospital hay chicos menores de cuatro años que si en el barrio están desnutridos, por falta de alimentación o no van a buscar la leche que se les brinda en el hospital porque no tienen dinero para el pasaje, por eso estamos brindando ese servicio que vengan del SAMCo a traerles las cosas y ponerle las vacunas acá en la escuela. (Mariel Mosconi, directora Escuela № 790 Pablo Pizzurno, entrevista del autor, abril de 2013)

El cosechero Mario, residente en el sector sur del distrito, da cuenta de las diferencias en cuanto a la atención médica entre su área de procedencia y el distrito de Coronda:

Cuando nos enfermamos vamos al hospital. Allá (en Chaco) nos quedaba bastante lejos. Teníamos que salir a medianoche para estar temprano sacar un turno y acá es como que todo es más cerca, porque vio que acá hay un dispensario. (Mario, cosechero, entrevista del autor, diciembre de 2012) 


\section{Importancia del acceso a la luz eléctrica}

Lo que debería ser una situación de lo más común vinculada con el progreso y modernismo, como es la disponibilidad de electricidad en la vivienda, más aún si consideramos que ya estamos atravesando la segunda década del siglo XXI, en ciertos lugares de la geografía de nuestro país todavía el acceso a la electricidad posee signos de elitismo. Tal es el caso en el área de procedencia de los cosecheros, puesto que, según sus relatos, en ocasiones solo los que residían en áreas urbanas contaban con el servicio de luz eléctrica. Esta situación, por un lado, lleva a la adopción de diversas estrategias para su reemplazo exponiendo a esta población a una mayor vulnerabilidad ante situaciones extremas, por ejemplo, de calor y frío y, por otro lado, limita el acceso a artefactos que hacen al ocio y recreación en la vida hogareña.

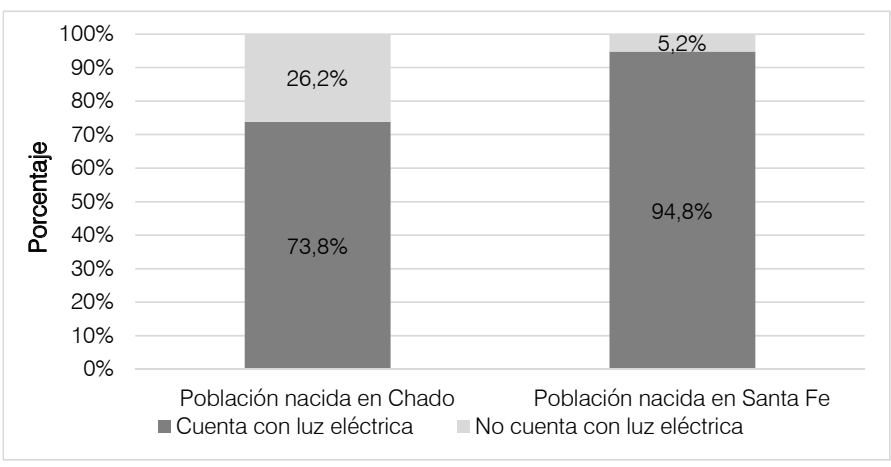

Figura 10. Distrito de Coronda. Población nacida en la provincia de Chaco y población total del distrito según cuente con electricidad. Año 2001.
Fuente: elaboración propia sobre la base de datos Censo de Población, Hogares y Viviendas. Año 2001 (INDEC).

Situación contraria ocurre en el área receptora; los sujetos, como lo refleja la Figura io, en su mayoría cuentan con acceso a electricidad. Aunque solo uno de todos los entrevistados manifestó que obtenía la electricidad de manera legal, el resto se encuadra en la categoría «enganchados», tal cual lo narra Miguel Ángel:

Estamos todos colgados, todo enganchado. Acá más de uno, si le permiten, quieren hacer su pilar, quiere tener una cosa buena porque a veces te pegan un voltaje de luz y te hace mierda todo entendés, lo que pasa es que como nosotros 
no tenemos, nos piden, que sé yo, un papel... (Miguel Angel, cosechero, entrevista del autor, enero de 2013)

El acceso al servicio eléctrico, de este modo, no cobra importancia por el hecho de la luminosidad propiamente dicha sino por el poder contar con artefactos que ayuden a mejorar la calidad de vida de estos sujetos, como, por ejemplo, ventiladores, aire acondicionado, calefactores, televisores, radiograbadores, computadoras, etc. Marcos comenta su situación tanto en el área de procedencia como en la de recepción:

En Chaco no existía la electricidad, allá usábamos vela y a leña los mecheros. Acá sí contamos con electricidad, podemos tener ventiladores, televisor, heladera, cosas que allá no se podían tener. (Marcos, cosechero, entrevista del autor, enero de 2013)

Igual realidad era la vivida por Pilar en el área expulsora, quien comenta: «allá teníamos que usar lamparita de mechero con kerosén; acá, electricidad» (Pilar, cosechera, entrevista del autor, enero de 2013). Por su parte, Jesús cuenta su situación:

«Allá no teníamos — luz-. Acá sí. Allá no teníamos nada porque quedaba lejos, donde estábamos nosotros quedaba a un kilómetro, y ahí teníamos que pagar no sé cuánto para que venga ese kilómetro, necesitábamos nosotros el cable de ahí arriba». (Jesús, cosechero, entrevista del autor, enero de 2013)

Los relatos antes desarrollados dan cuentan de las falencias en servicios básicos con las que esta población contaba en su lugar de origen. Por otra parte, en el caso particular del acceso a la electricidad, este presenta una relación directa con la mejora en las condiciones de vida a través del acceso a electrodomésticos de gran utilidad, más aún si consideramos las condiciones de ambientales, en especial por la temperatura imperante en el área receptora, pero, en especial, la de expulsión. De esta manera, el poder contar con heladera, calefactores, ventiladores, se convierte en una necesidad de primera importancia. También podemos identificar necesidades secundarias, como contar con televisión (y el acceso a la televisión satelital, característica de las áreas rurales, donde la cobertura de televisión por cable es inexistente), telefonía celular, computadoras, 
etc. Artefactos todos que, como se mencionó, indirectamente hacen a una mejora en la calidad de vida, en especial por medio de la comunicación y recreación de las personas.

\section{Conclusiones}

El abandono de la modalidad migratoria estacional por parte de los cosecheros de frutilla oriundos de Chaco implicó la radicación definitiva en el distrito de Coronda con el objetivo de mejorar sus condiciones de vida y su vez superar las situaciones de precariedad que son parte de la historia de vida de estos.

Las malas condiciones laborales, exposiciones a temperaturas extremas en las explotaciones y su vivienda, los vínculos con diversos actores sociales en la comunidad receptora que, si bien no provocan situaciones de discriminación, tampoco logran una integración social acorde a la importancia de su presencia en el distrito, remiten a tiempos en los que eran migrantes golondrinas.

No obstante, dentro de este contexto activan diferentes estrategias familiares de reproducción orientadas a superar situaciones históricas de postergación; estas se han enfocado primordialmente a una mayor estabilidad laboral junto a la posibilidad de desarrollar empleos alternativos a la producción de frutilla; el acceso a vivienda, satisfacción de necesidades vinculadas a servicios básicos que les eran denegados, como el uso de electricidad, agua, cobertura médica, educación, entre otros. Este escenario lleva a que una de las frases recurrentes en las diversas entrevistas realizadas a los cosecheros sea: «acá hay más vida", al referirse a la superación de sus condiciones de vida en el distrito de Coronda con respecto a la de sus lugares de procedencia. 


\section{Referecnias bibliográficas}

Bardomás, S. (2012). La migración estacional a producciones agrarias de un área de Argentina: el Valle de Uco, provincia de Mendoza. Papeles de población, I8(72), 39-62. Recuperado de: http://www.scielo.org.mx/scielo. php?script=sci_arttext\&pid=SI405-742520I200020000 3\&lng=es\&tlng=es (acceso 4 de enero de 20I4).

Bendini, M.; Radonich, M. y Steimbreger, N. (2006). Los trabajadores agrícolas estacionales. Marco teórico-metodológico para un estudio de caso. Teoría \& Pesquisa, 49, I13-139. Recuperado de: http://www.teoriaepesquisa. ufscar.br/index.php/tp/article/viewFile/22/I4 (acceso 2 de marzo de 2013). (2012). Historia de la vulnerabilidad social de los «golondrinas» en la cuenca frutícola del Río Negro. En Bendini, M.; Steimbreger, N. et al. (Coords.). Trabajo rural y travesias migratorias. Neuquén: Educo. (2014). Continuidades y cambios en la migración estacional. En Benencia, R.; Cánovas, A. y Quaranta, G. (Coords.). Mercados de trabajo. Instituciones y trayectorias en distintos escenarios migratorios. Buenos Aires: CICCUS.

Benencia, R.; Giarracca, N. (Coord.) (1999). Aspectos metodológicos de una investigación sobre población y salud en áreas rurales. El uso de indicadores simples y complejos. En Estudios rurales. Teorias, problemas y estrategias metodológicas. Buenos Aires: La Colmena.

Domenach, H. y Celton, D. (1998). La comunidad Boliviana en Córdoba. Caracterización y procesos migratorios. Córdoba: UNC. CEA.

Fantín, A. (2008). Población, sociedad y salud en la frontera argentino-paraguaya. Asunción: ADEPO-UNFPA.

Pértile, V. (20I3). Características sociales del pequeño productor del centro y sudoeste chaqueño a fines de los 9o. Recuperado de: http://hum.unne.edu. $\mathrm{ar} /$ revistas/geoweb/Geo5/contenidos/carsoc5.htm (5 de febrero de 20I4).

Reboratti, C. (1979). Migraciones y frontera agraria: Argentina y Brasil en la cuenca del Alto Paraná-Uruguay. Cuaderno del CENEP No 8. Buenos Aires: Centros de Estudio de la Población.

Sabalain, C. y Reboratti, C. (1980). Vendimia, zafra y alzada: migraciones estacionales en la Argentina. Cuaderno del CENEP No Is. Buenos Aires: Centros de Estudio de la Población. 